\title{
$\begin{array}{ll}\text { Research Square } & \begin{array}{l}\text { Preprints are preliminary reports that have not undergone peer review. } \\ \text { They should not be considered conclusive, used to inform clinical practice, }\end{array} \\ \text { or referenced by the media as validated information. }\end{array}$
}

\section{Synthesis of Silver Nanoparticles From Indian Red Yeast Rice and Its Inhibition of Biofilm in Copper Metal in Cooling Water Environment}

\section{Muthukumar Suganya}

Mother Teresa Women's University Centre for Women's Studies

Parameswaran Sujatha Preethi

Mother Teresa Women's University Centre for Women's Studies

Jayaraman Narenkumar

Bharath Institute of Higher Education and Research

Arumugam Arul Prakash

Thiruvalluvar University

\section{Sandhanasamy Devanesan}

King Saud University College of Science

Mohamad S. AlSalhi

King Saud University College of Science

Aruliah Rajasekar ( $\square$ rajasekargood@gmail.com )

Thiruvalluvar University

Ayyakkannu Usha Raja Nanthini

Mother Teresa Women's University Centre for Women's Studies

\section{Research Article}

Keywords: Red yeast rice extract, Silver nanoparticle, Copper metal, Biocorrosion, Cooling water system

Posted Date: February 17th, 2022

DOI: https://doi.org/10.21203/rs.3.rs-1179555/v1

License: (c) (1) This work is licensed under a Creative Commons Attribution 4.0 International License. Read Full License 


\section{Abstract}

The development of environmentally acceptable benign techniques using purely natural methods is a cost-effective procedure with long-term benefits in all areas. With this consideration, myco synthesized silver nano particles (AgNPs) were studied and it acted as an impending corrosion inhibitor in the environment. Initially, AgNPs was evaluated by physical and surface characterizations and this evidence demonstrated that RYRE's water-soluble molecules played an essential role in the synthesis of AgNPs in nano spherical size. The myco synthesized of AgNPs has showed an antibacterial activity against corrosive bacteria in Cooling Water System (CWS). Hence, the AgNPs were used in biocorrosion studies as an anticorrosive agent along with $\mathrm{AgNO}_{3}$ and RYRE was also checked. For this experiment, the copper $\mathrm{Cu}$ ) metal (CW024) which is commonly used was selected, the result of corrosion rate was decreased and inhibition efficiency (82\%) was higher in the presence of AgNPs in system IV. Even though, $\mathrm{AgNO}_{3}$ and RYRE had contributed significant inhibition efficiency on $\mathrm{Cu}$ at $47 \%$ and $61 \%$ respectively. According to XRD, the reaction of AgNPs on Cu metal resulted in the formation of a protective coating of $\mathrm{Fe}_{2} \mathrm{O}_{3}$ against corrosion. EIS data also indicated that it could reduce the corrosion on the Cu metal surface. All of these findings point out the possibility that the myco synthesized AgNPs were an effective copper metal corrosion inhibitor. As a result, we encourage the development of myco-synthesized AgNPs, which could be useful in the industrial settings.

\section{Introduction}

Bio-corrosion is one of the leading industrial problems that can cause extreme damage to expensive equipment/instruments and consequently bring about great economic loss in the maintenance at industrial sector (Guo et al., 2018; Narenkumar et al., 2017). Due to the microbial activity, metal deterioration appears in the cooling tower which is known as Microbial Influenced Corrosion (MIC). The microorganisms can change the chemical compounds on the surfaces of metals by metabolic activity, which can affect the metal's interface chemical bond (Narenkumar, et al., 2018; Beech \& Sunner, 2004). There are many negative impacts influenced by microorganisms and their by-products on heat transfer in the cooling tower (Rajasekar and Yen, 2014). Whereas, increasing the bacterial community's resistance to heavy metals is a significant risk worldwide (lanieva, 2009; Wood \& Wang, 1983).

$\mathrm{Cu}$ is the most commonly used metal for cooling towers in many industries as they have good conductivity, higher corrosion resistance behavior, and excellent insulating properties (Narenkumar et al., 2019). Although on the contrary, several research work have found that $\mathrm{Cu}$ alloys are subjected to MICinduced pitting and crevice corrosion. (Javed et al., 2016; Lytle \& Nadagouda, 2010; Warraky et al., 2004). The metal content of copper with the minimum amount of nickel alloys is susceptible to several types of localized corrosion (Little, et al., 1991). Meanwhile, microbes accelerate the material deterioration which causes the high release of Cu byproducts in the water bodies (Critchley et al., 2004; Reyes et al., 2008). Therefore several techniques (mechanical, chemical, electrochemical and biological etc.) have been performed to reduce the biocorrosion in CWS (X. L. Li et al., 2018; Narenkumar, et al., 2017). Aside from the natural methods, most of these approaches are expensive and deemed detrimental to the 
environment (Dalmoro et al., 2012). Consequently, researchers are involved in exploration of the natural by-products as potent corrosion inhibitors due to the tremendous biological availability in the environment.

Myco-nanoparticle synthesis is one of the biosynthetic methods, which involves fungus for the synthesis of nanoparticle. A large number of fungal strains are capable of synthesizing metal nanoparticles (Dinarvand et al., 2017). A large number of physical and chemical methods which is used to synthesize nanoparticles are expensive and possess serious threat to the biological system. Relatively successful, biosynthetic methods can be suitable alternative, as they are safe, more effective, eco-friendly (Ahmed et al., 2016) and they have risk-free synthesis procedures(Khalilzadeh \& Borzoo, 2016). In that way, myco synthesized nanoparticles have more potential activities due to their bioavailability, cost-effective and less toxicity (Azmath et al., 2016; Madakka et al., 2018). The beneficial fungi, Monascus ruber produces more secondary metabolites which have many medicinal properties (Lachenmeier et al., 2012) and it has been used for producing fermented food product known as angakak or red yeast rice in East Asian countries. It is also used as traditional medicine for over 1000 years (Wang \& Lin, 2007).

The present study has been to synthesis silver nanoparticles using Red Yeast Rice (RYR) and to evaluate their anti-biocorrosion activity on Cu metal in cooling water system.

\section{Materials And Methods}

\section{Fungal culture and chemical}

The Monascus ruber (460) was obtained from MTCC, Chandigarh, India. The culture kept at $4^{\circ} \mathrm{C}$ on Potato Dextrose Agar (PDA) and was sub cultured periodically. Silver nitrate chemical (AgNO3) was obtained from Sigma Aldrich.

\section{Preparation of Red Yeast Rice powder and Extract}

The culture of M. ruber was inoculated in steamed rice and was kept for solid-state fermentation in 250 $\mathrm{mL}$ Erlenmeyer flask for 14 days at $30^{\circ} \mathrm{C}$. After that, the fermenting rice was dried and ground (Ferdes et al., 2009). The Red Yeast Rice Extract (RYRE) was obtained by extracting the final product of RYR with water (ratio $1: 10 \mathrm{w} / \mathrm{v}$ ) at $70^{\circ} \mathrm{C}$ for 15 minutes.

\section{Silver nanoparticles synthesis}

A reaction mixture of RYRE and $1.5 \mathrm{mM}$ AgNO3 solution in a ratio of 1:9 was used. The primary confirmation of colour change observed by visual observation and was confirmed at $420 \mathrm{~nm}$ in UV Vis spectrophotometer. In centrifugation, sedimentation was separated at 12,000 rpm for $15 \mathrm{~min}$. To ensure purity, the collected sedimentation was re dispersed in deionized water and centrifuged again (Phongtongpasuk et al., 2016). Then, dried the final particles and analyzed the characterization by FTIR, XRD and TEM. 


\section{Biocorrosion Studies}

\section{Cultures}

In this experiment, Bacillus thuringiensis (EN2), Terribacillus aidingensis (EN3) and Bacillus oleronius (EN9) strains were used, these strains are found to be dominant in the biofilm sample of CWS and was isolated and identified by Narenkumar et al., (2018). EN2, EN3, and EN9 sequences were submitted to the National Center for Biotechnology Information (NCBI) with the accession numbers KR183873, KR183874, and KR183880. All of the strains were kept in glycerol stock and maintained the sub cultured in sterile nutrient agar (NA) plates.

\section{Agar well diffusion assay}

The antibacterial activity of AgNPs and RYRE on Muller Hinton Agar was determined using the well diffusion method. MHC agar plates were prepared and $0.1 \mathrm{ml}$ of bio-corrosive strains (EN2, EN3, and EN9) was uniformly spread under aseptic condition. The wells were cut by cork borer and filled with 50ppm of RYRE, 10, 50 and 100ppm of AgNPs respectively. In the remaining wells, as a positive control, Tetracycline $(10 \mu \mathrm{g})$ was used, because it's having wide range of bacterial resistance and as a negative control, sterile distilled water was used on the plate. These plates were performed in triplicates and incubated for 24 hours at 370C. After that, the diameter of the inhibition zones was measured.

\section{Biofilm formation assay}

This biofilm assay technique on AgNPs was done by following Narenkumar et al., 2018a. 24 hours culture of EN2, EN3, and EN9 were inoculated in nutrient broth (NB) medium and diluted to 1:20 ratio with fresh NB medium.100 $\mu$ mixed consortium was transfer into a 96- well microliter plate followed by 50ppm of AgNPs were added and incubated at $370 \mathrm{C}$ for $24 \mathrm{hrs}$. After the incubation, the culture was removed and rinsed with phosphate buffer saline (137 Mm NaCl, $2.7 \mathrm{mM} \mathrm{KCl}, 10 \mathrm{mM} \mathrm{NaHPO}, 2 \mathrm{mM} \mathrm{KHPO}, \mathrm{pH} 7.2$ ) and then with distilled water. After that, $120 \mu \mathrm{l}$ of crystal violet was added and incubated at $370 \mathrm{C}$ for 20 min then rinsed with distilled water. In the end, $125 \mu \mathrm{l}$ of acetic acid added and the mixture incubated at $37^{\circ} \mathrm{C}$ for $15 \mathrm{~min}$. The final product was examined using UV-visible spectrophotometer set to $600 \mathrm{~nm}$.

\section{Bio corrosion studies}

For this study, Cu CW024 was chosen and tested for Corrosion Rate (CR); Electrochemical Impedance Studies (EIS) and surface analysis. The coupon size was around $2.5 \mathrm{~cm} 2$ and $1.5 \mathrm{~cm} 2$ and the metal composition wt (\%) was zinc 0.03 , tin 0.01 , manganese 0.65 , nickel 6.09 , silicon 0.004 , iron 1.41 , lead 0.01 and remaining $91.79 \mathrm{Cu}$. The experimental system strategy is given in table: 1 . briefly, the copper metal coupons were polished and the coupons were immersed in $400 \mathrm{~mL}$ CTW containing $1 \%$ of sterile NB medium in $500 \mathrm{ml}$ Erlenmeyer flask and was denoted as control. The system I consisted of control inoculated with $1 \mathrm{ml}$ of each bio corrosive strains (consortia) at $1.3 \times 105 \mathrm{CFU} / \mathrm{mL}$ in a $500 \mathrm{ml}$ Erlenmeyer flask. System II comprised of system I and added 50ppm of AgNO3 alone. Whereas, System III comprised of system I with 50 ppm of RYRE and system IV comprised of system I with 50 ppm of AgNPs. To 
analyses corrosion rates, all experiments were performed in triplicate coupons and kept in room temperature for 14 days in a static condition.

\section{Corrosion rate (CR) and weight loss (WL) measurements}

After the incubation, the surface biofilm was scraped off from the Cu coupons in respective bio corrosive systems. Collected samples were dried and crushed into fine powder then the samples were characterized by FTIR and XRD (Bruker-8030). To analysis the WL, the Cu coupons were soaked with pickling solution (1 Liter of H2Oand $500 \mathrm{~mL}$ of $\mathrm{HCL}$ ) for $25 \mathrm{~min}$ at room temperature and then, the average $\mathrm{WL}$ and $\mathrm{CRs}$ of the metals were calculated using a standard method (Preethi et al., 2019a).

\section{Electrochemical measurement}

EIS contains three types of electrode systems (CH Instrument Inc., USA model CHI- 608E): Cu coupons were chosen as the working electrode, while $\mathrm{Ag} / \mathrm{Agcl}$ was used as the reference electrode and for counter electrode platinum wire was used. These electrodes were used to detect Impedance and Tafel polarisation. (Bellon et al.,1996).

\section{Result And Discussion}

\section{Biosynthesis of AgNPs}

The preparation of RYR (Fig:1a) and RYRE were carried out by the procedure mentioned in material and methods. A reaction mixture color was then changed from pale red to dark brown as seen visually (Fig:1b). This brown color indicated the formation of AgNPs as a result of $\mathrm{Ag}+$ ion reduction in the reaction solution (Gurunathan et al., 2009) which was confirmed by UV-Vis spectroscopy at $420 \mathrm{~nm}$ with specific excitation of Surface Plasmon Resonance in Fig:1c (Sharma et al., 2018). It was concluded that the cell-free extract of RYRE is suitable for synthesis of silver nanoparticles because it contains high amount of amino acids (Abdul et al., 2017), polysaccharide (Srianta et al., 2014) and total phenols and flavonoids (Hasim et al., 2018). As a reducing and stabilizing agent, these compounds are taking part in the formation of AgNPs synthesis. (Aritonang et al., 2019; Marslin et al., 2018).

\section{Characterization of AgNPs}

FTIR analysis of AgNPs (Fig:1d) revealed that seven distinct functional groups are present in the sample. The O-H stretch of alcohol and phenols is indicated by the prominent and broad transmittance peak at $3433.33 \mathrm{~cm}^{-1}$. The primary amines and secondary amines of amino acids, peptides and proteins are indicated by the bonds made at $2925.86 \mathrm{~cm}^{-1}$ and $1626.61 \mathrm{~cm}^{-1}$ for $\mathrm{C}-\mathrm{H}$ stretching alkanes and $\mathrm{N}-\mathrm{H}$ stretch, respectively, which enhance the stability of synthesized nanoparticles (Tai et al., 2014) The phosphorus or sulfur function groups, which might also link with silver and act as both capping and stabilizing agent of nanoparticles, it can be attributed to the peak at $1432.48 \mathrm{~cm}^{-1}$ and $1079.04 \mathrm{~cm}^{-1}$ correlated with C-C stretch (Hamouda et al., 2019). C-O stretch alcohol, carboxylic acid and $762.82 \mathrm{~cm}^{-1}$ 
and $669.20 \mathrm{~cm}^{-1}$ corresponded to alkenes. Hence, these biomolecules are considered to be responsible for efficiently capping and stabilizing AgNPs.

The distraction intensity was recorded from 200 to 800 at $2 \theta$ angle based on the XRD data (Fig: 1e). It indicates 6 strong intensity peaks at $32.40,33.58,38.20,44.42,64.59$, and 77.53 , which corresponded to the Centro symmetric structural planes $122,212,123,312,241$, and 137. All of these peaks are quite similar to the JCPDS file number 00-043-0649. Using the Scherrer formula, the average crystallite particle size was calculated to be $6.46 \mathrm{~nm}$ (Fig: 1f). According to the TEM, the particles nano size ranged from $6.81 \mathrm{~nm}$ to $30.93 \mathrm{~nm}$ in diameter, and their shape was spherical (Fig:1f and g).

\section{Antibacterial activity}

Myco-synthesized AgNPs was tested for antibacterial activity against bacterial consortium with agar well diffusion method. AgNPs had the highest activity at 100ppm and the lowest activity at $10 \mathrm{ppm}$, with moderate inhibition at 50ppm. When compared to other concentrations of AgNPs, the zone of inhibition shown by RYRE was relatively moderate. According to several reports, AgNPs are an effective antibacterial agent that breaks the chemical bonds of the bacterial wall and causes cell death. (Le Ouay \& Stellacci, 2015; J. Li et al., 2013). Based on the findings, 50ppm of AgNPs was chosen as Minimal Inhibitory Concentration (MIC) for further bio corrosion study.

\section{Biofilm formation assay}

Crystal violet was used for the biofilm formation assay on a microliter plate (Toole et al., 1999). The consortium has formed biofilm on the outer surface after 24 hours of incubation, in contrast, there was no biofilm formation appeared in AgNPs (fig:2). The foregoing results were shown AgNPs had the ability to inhibit biofilm growth on the surface.

\section{Biocorrosion studies}

\section{Weight loss and corrosion rate}

WL and CR of copper coupons was calculated (table 2). In abiotic condition, the average weight loss of the control system was around $0.0016 \pm 1$, whereas the system I had maximum amount of weight loss about $0.0039 \pm 2$. System II and system III had about $0.0008 \pm 2$ and $0.00060 \pm 1$ and the inhibition efficiency was about $47 \%$ and $61 \%$ respectively. These results were shown that the presence of $\mathrm{AgNO}_{3}$ and RYRE compounds is acting against the host bacteria in CWS.

The presence of AgNPs in system IV resulted in a considerable weight reduction of $0.00027 \pm 2$ and the inhibition efficiency was $82 \%$ that is higher when compare than other systems. All Corrosion rate were calculated from average weight loss about $0.017,0.042,0.009,0.006$ and $0.002 \mathrm{~mm} / \mathrm{y}$ respectively. Metal weight loss generally occurred by the formation of biofilm on metal surface, which caused pitting corrosion, mainly in $\mathrm{Cu}$, due to metal oxidation (Preethi et al., 2019a). From these experiments, the results indicated that system IV had lower WL and CR and have found high inhibition efficiency. Finally, myco 
synthesized AgNPs have an important role in CWS as an effective inhibitor of biofilm formation as well as a reduction in Cu metal corrosion.

\section{Surface analysis}

XRD was used to characterize the corrosion products obtained from each experimental system (Fig:3). The control system listed all of the peaks and their compounds, and that peak intensity was compared to other experimental systems. The high-intensity peaks were observed in $2 \theta$ ranges of 35,45 , and 55 , indicating $\mathrm{Cu}(\mathrm{OH})_{2}, \mathrm{Cu}_{2} \mathrm{O}$, and $\mathrm{NiCuO}_{3}$ compounds, respectively, and the low-intensity peaks were found at $2 \theta$ ranges of 65 and 75 , indicating the compounds $\mathrm{Mn}_{2} \mathrm{O}_{4}$ and $\mathrm{Fe}_{2} \mathrm{O}_{3}$, respectively.

The peak intensity of $\mathrm{Cu}(\mathrm{OH})_{2}$ was found in all experimental system. Besides, $\mathrm{Cu}_{2} \mathrm{O}$ peak was significantly reduced from system II to IV due to the activity of $\mathrm{AgNO}_{3}, \mathrm{RYRE}$, and $\mathrm{AgNPs}$, respectively. Consortia and $\mathrm{AgNO}_{3}$ indicate that system I and system II exhibited a partially reduced peak at $\mathrm{NiCuO}_{3}$, but $\mathrm{NiCuO}_{3}, \mathrm{Mn}_{2} \mathrm{O}_{4}$, and $\mathrm{Fe}_{2} \mathrm{O}_{3}$ were absent in the RYRE-contained system III, demonstrating that RYRE can reduce corrosion. When compared to other systems, the intensity of $\mathrm{Cu}(\mathrm{OH})_{2}$ and $\mathrm{Cu}_{2} \mathrm{O}$ peaks was reduced in system IV, whereas $\mathrm{NiCuO}_{3}$, and $\mathrm{Mn}_{2} \mathrm{O}_{4}$ disappeared. Those peak intensities have decreased and vanished, indicating that $\mathrm{Cu}$ metal is less corroded. In system IV, the peak in $\mathrm{Fe}_{2} \mathrm{O}_{3}$ was higher than others, indicating that the adhesion of AgNPs on $\mathrm{Cu}$ metal can be reacted with $\mathrm{Fe}_{2} \mathrm{O}_{3}$ via the oxidation process (Touati, 2000). Similarly, Narenkumar et al., (2017) found that the adsorption of AgNPs on mild steel formed a protective film with Fe compound, acted to protect the metal from corroding. Furthermore, $\mathrm{Ag} / \mathrm{Fe}_{2} \mathrm{O}_{3}$ nanoparticles showed a significantly higher antibacterial effect than $\mathrm{Fe}_{2} \mathrm{O}_{3}$ alone (Kareem et al., 2018). In system IV, the oxidation process of Fe and AgNPs compound was clearly found to decrease corrosion. As a result, we confirmed AgNPs as a positive inhibitor that created a protective coating on $\mathrm{Fe}_{2} \mathrm{O}_{3}$ compound of the surface of $\mathrm{Cu}$ metal, which inhibits biofilm formation and prevents corrosion in the CWS.

\section{Electrochemical Impedance Studies (EIS)}

Electrochemical impedance results are presented in the Table 3 and Figs. 4 and 5. The control system's corrosion current $\left(I_{\text {corr }}\right)$ was around $3.6 \times 10^{-7} \mathrm{~A} / \mathrm{cm}^{2}$ and in system I mixed consortium was higher at $4.7 \times 10^{-7} \mathrm{~A} / \mathrm{cm}^{2}$. In system II, the addition of $\mathrm{AgNO}_{3}$ resulted in an $I_{\text {corr }}$ of about $3.5 \times 10^{-7} \mathrm{~A} / \mathrm{cm}^{2}$, while in system III, the addition of RYRE resulted in an $I_{\text {corr }}$ of about $4.6 \times 10^{-6} \mathrm{~A} / \mathrm{cm}^{2}$. The corrosion current in system IV with AgNPs was about $3.3 \times 10^{-6} \mathrm{~A} / \mathrm{cm}^{2}$. System I had the higher corrosion current because of the growth of microbes on the Cu surface therefore, anodic cite current density was shifted to cathodic cite that indicates the higher level of corrosion occurred in Cu metal (Narenkumar, et al., 2017; Rajasekar et al., 2007). According to Preethi et al., 2019; Rajasekar et al., 2005 when corrosion occurs, the Cu ions breakdown on the metal surface, which stimulates the formation of pits. According to the results, when compared to other systems, system IV showed lower corrosion current density indicating that it had 
achieved less metal corrosion. System III outperforms system II by the $I_{\text {corr }}$ value. From this EIS data, it is clear that, AgNPs have the capability to prevent corrosion on Cu metal used in CWS.

\section{Conclusion}

Current investigation highlighted the significance of an industrial complication, which is commonly found in CWS, and dealt with the issue by using fungi-based RYRE mediated AgNps. We successfully developed an environmentally friendly synthesis method for AgNps, with formulation and characterization confirmed by physical examination. In biocorrosion experiments, AgNps exhibited strong antibacterial properties against the corrosive bacteria of CWS and have been found to be a possible corrosive inhibitor against biofilm formation, resulting in a reduction in Cu metal CR. According to XRD results, AgNPs reacted with $\mathrm{Cu}$ metal to form $\mathrm{Fe}_{2} \mathrm{O}_{3}$ compound, which serves as a protective coating on the $\mathrm{Cu}$ surface, in addition to, EIS data also proved that the significant indication on Cu metal. Furthermore, RYRE and $\mathrm{AgNO}_{3}$ were found to be capable of minimizing Cu corrosion rate and have the evidence of inhibition efficiency in all studies. As a result, we hypothesized that myco-synthesized AgNPs could be an effective inhibitor to prevent corrosion from corrosive bacteria in CWS and that it could be used in the development of anti-biofilm agents, a promising corrosion application.

\section{Declarations}

\section{Acknowledgment}

The authors are grateful to the Researchers Supporting Project Number (RSP-2021/398), King Saud University, Riyadh, Saudi Arabia.

Conflicts of interest/Competing interests: All authors hereby declare that there is no conflict of interest.

Ethics approval: Not applicable.

Consent to participate: Not applicable.

Consent for publication: All authors agreed to publish this version of the article.

Funding: Not applicable.

Availability of data and materials: The datasets used and analyzed during the current study are available from the corresponding author on reasonable request.

\section{Authorship contribution statement}

Muthukumar Suganya: Experimental work, Field collection, Writing - original draft, Writing - review \& editing. Parameswaran Sujatha Preethi: Writing, experimental validation \& results and discussion. Jayaraman Narenkumar: Writing - review \& editing. Arumugam Arul Prakash. Sandhanasamy 
Devanesan: Validation, Formal analysis, Acquiring and analysis of XRD and EIS. Mohamad S. AlSalhi: Resources, Funding acquisition. Aruliah Rajasekar: Data analysis, manuscript editing, and results and discussion. Ayyakkannu Usha Raja Nanthini: Project administration, Supervision, Validation, Writing review \& editing.

\section{References}

1. Ahmed S, Ahmad M, Swami BL, Ikram S (2016) A review on plants extract mediated synthesis of silver nanoparticles for antimicrobial applications: A green expertise. J Adv Res 7(1):17-28

2. Antioxidant Activity of Ethanol Extract ofRed Yeast Rice and its Fractionation Products

3. Aritonang HF, Koleangan H, Wuntu AD (2019) Synthesis of Silver Nanoparticles Using Aqueous Extract of Medicinal Plants' (Impatiens balsamina and Lantana camara) Fresh Leaves and Analysis of Antimicrobial Activity. International Journal of Microbiology, 2019, 1-8

4. Azmath P, Baker S, Rakshith D, Satish S (2016) Mycosynthesis of silver nanoparticles bearing antibacterial activity. Saudi Pharmaceutical Journal 24(2):140-146

5. Beech IB, Sunner J (2004) Biocorrosion: Towards understanding interactions between biofilms and metals. Curr Opin Biotechnol 15(3):181-186

6. Bellon-Fontaine M-N, Rault J, van Oss CJ (1996) Microbial adhesion to solvents: A novel method to determine the electron-donor/electron-acceptor or Lewis acid-base properties of microbial cells. Colloids Surf, B 7(1-2):47-53

7. Critchley MM, Pasetto R, O'Halloran RJ (2004) Microbiological influences in "blue water" copper corrosion. J Appl Microbiol 97(3):590-597

8. Dalmoro V, dos Santos JHZ, Armelin E, Alemán C, Azambuja S, D (2012) Phosphonic acid/silicabased films: A potential treatment for corrosion protection. Corros Sci 60:173-180

9. Dinarvand M, Rezaee M, Foroughi M (2017) Optimizing culture conditions for production of intra and extracellular inulinase and invertase from Aspergillus niger ATCC 20611 by response surface methodology (RSM). Brazilian Journal of Microbiology 48(3):427-441

10. Ferdes M, Camelia U, Nicoleta R, Ana AC (2009) Anti microbial effect of monascus purpureus red rice against some bacterial and fungal strains. Chemical Engineering Transactions, 17

11. Guo J, Yuan S, Jiang W, Lv L, Liang B, Pehkonen SO (2018) Polymers for Combating Biocorrosion. Frontiers in Materials

12. Gurunathan S, Kalishwaralal K, Vaidyanathan R, Venkataraman D, Pandian SRK, Muniyandi J, Hariharan N, Eom SH (2009) Biosynthesis, purification and characterization of silver nanoparticles using Escherichia coli. Colloids Surf, B 74(1):328-335

13. Hamouda RA, Hussein MH, Abo-elmagd RA, Bawazir SS (2019) Synthesis and biological characterization of silver nanoparticles derived from the cyano bacterium Oscillatoria limnetica. Sci Rep 9(1):13071

14. Hasim, Andrianto D, Islamiati W, Ham W (2018) A.F., Nur Farida, D., 
15. lanieva $O$ (2009) Mechanisms of bacteria resistance to heavy metals. Mikrobiol Z 71(6):54-65

16. Javed MA, Neil WC, Adam GM, Wade SA (2016) Microbiologically Influenced Corrosion of Copper and its Alloys - A Review. Corrosion \& Prevention,84

17. Kareem ZH, Shareef HK, Alkaim AF (2018) Evaluation of antibacterial activity of Fe2O3 nanoparticles against Shigella dysenteriae. Journal of Pharmaceutical Science and Research 10(8):1980-1982

18. Khalilzadeh MA, Borzoo M (2016) Green synthesis of silver nanoparticles using onion extract and their application for the preparation of a modified electrode for determination of ascorbic acid. Journal of Food and Drug Analysis 24(4):796-803

19. Lachenmeier DW, Monakhova YB, Kuballa T, Löbell-Behrends S, Maixner S, Kohl-Himmelseher M, Waldner A, Steffen C (2012) NMR evaluation of total statin content and HMG-CoA reductase inhibition in red yeast rice (Monascus spp.) food supplements. Chin Med 7(1):8

20. Le Ouay B, Stellacci F (2015) Antibacterial activity of silver nanoparticles: A surface science insight. Nano Today 10(3):339-354

21. Li J, Rong K, Zhao H, Li F, Lu Z, Chen R (2013) Highly Selective Antibacterial Activities of Silver Nanoparticles Against Bacillus subtilis. J Nanosci Nanotechnol 13(10):6806-6813

22. Li XL, Narenkumar J, Rajasekar A, Ting YP (2018) Biocorrosion of mild steel and copper used in cooling tower water and its control. 3 Biotech 8(3):178

23. Little B, Wagner P, Ray R, Jones JM (1991) Microbiologically Influenced Corrosion of Copper Alloys in Saline Waters Containing Sulfate-Reducing Bacteria. Corrosion91, 101

24. Lytle DA, Nadagouda MN (2010) A comprehensive investigation of copper pitting corrosion in a drinking water distribution system. Corros Sci 52(6):1927-1938

25. Madakka M, Jayaraju N, Rajesh N (2018) Mycosynthesis of silver nanoparticles and their characterization. MethodsX 5:20-29

26. Marslin G, Siram K, Maqbool Q, Selvakesavan R, Kruszka D, Kachlicki P, Franklin G (2018) Secondary Metabolites in the Green Synthesis of Metallic Nanoparticles. Materials 11(6):940

27. Narenkumar J, Elumalai P, Subashchandrabose S, Megharaj M, Balagurunathan R, Murugan K, Rajasekar A (2019) Role of 2-mercaptopyridine on control of microbial influenced corrosion of copper CW024A metal in cooling water system. Chemosphere 222:611-618

28. Narenkumar J, Parthipan P, Madhavan J, Murugan K, Marpu SB, Suresh AK, Rajasekar A (2018) Bioengineered silver nanoparticles as potent anti-corrosive inhibitor for mild steel in cooling towers. Environ Sci Pollut Res 25(6):5412-5420

29. Narenkumar J, Parthipan P, Usha Raja Nanthini A, Benelli G, Murugan K, Rajasekar A (2017) Ginger extract as green biocide to control microbial corrosion of mild steel. 3 Biotech 7(2):133

30. Narenkumar J, Ramesh N, Rajasekar A (2018) Control of corrosive bacterial community by bronopol in industrial water system. 3 Biotech 8(1):55

31. Narenkumar J, Sathishkumar K, Sarankumar RK, Murugan K, Rajasekar A (2017) An anticorrosive study on potential bioactive compound produced by Pseudomonas aeruginosa $\mathrm{TBH} 2$ against the 
biocorrosive bacterial biofilm on copper metal. J Mol Liq 243:706-713

32. Phongtongpasuk S, Poadang S, Yongvanich N (2016) Environmental-friendly Method for Synthesis of Silver Nanoparticles from Dragon Fruit Peel Extract and their Antibacterial Activities. Energy Procedia 89:239-247

33. Preethi PS, Narenkumar J, Prakash AA, Abilaji S, Prakash C, Rajasekar A, Nanthini AUR, Valli G (2019a) Myco-Synthesis of Zinc Oxide Nanoparticles as Potent Anti-corrosion of Copper in Cooling Towers. J Cluster Sci 30(6):1583-1590

34. Rajasekar A, Ganesh Babu T, Maruthamuthu S, Karutha Pandian ST, Mohanan S, Palaniswamy N (2007) Biodegradation and corrosion behaviour of Serratia marcescens ACE2 isolated from an Indian diesel-transporting pipeline. World Journal of Microbiology and Biotechnology 23(8):10651074

35. Rajasekar A, Maruthamuthu S, Muthukumar N, Mohanan S, Subramanian P, Palaniswamy N (2005) Bacterial degradation of naphtha and its influence on corrosion. Corros Sci 47(1):257-271

36. Rajasekar A, Yen-Peng T (2014) Characterization of Corrosive Bacterial Consortia Isolated from Water in a Cooling Tower. ISRN Corrosion, 2014, 1-11

37. Research Journal of Phytochemistry, 12(2),52-59

38. Reyes A, Letelier MV, De la Iglesia R, González B, Lagos G (2008) Microbiologically induced corrosion of copper pipes in low-pH water. Int Biodeterior Biodegrad 61(2):135-114

39. Samat N, Kasran M, Hassan H (2017) Proximate and amino acids composition of Monascus fermented products with potential as functional feed ingredients. Cogent Food \& Agriculture, 3(1)

40. Sharma G, Nam JS, Sharma A, Lee SS (2018) Antimicrobial Potential of Silver Nanoparticles Synthesized Using Medicinal Herb Coptidis rhizome. Molecules 23(9):2268

41. Srianta I, Ristiarini S, Sen SK, Zhang BB, Xu GR, Blanc P, Nugerahani I (2014) Recent research and development of Monascus fermentation products. International Food Research Journal 21(1):1-12

42. Tai JT, Lai CS, Ho HC, Yeh YS, Wang HF, Ho RM, Tsai DH (2014) Protein-Silver Nanoparticle Interactions to Colloidal Stability in Acidic Environments. Langmuir 30(43):12755-12764

43. Toole O, Pratt LA, Watnick PI, Newman DK, Weaver VB, Kolter R (1999) Genetic approaches to study of biofilms.. In Methods in Enzymology, vol 310. Elsevier, pp 91-109

44. Touati D (2000) Iron and Oxidative Stress in Bacteria. Arch Biochem Biophys 373(1):1-6

45. Wang T, Lin T (2007) Monascus Rice Products.. In Advances in Food and Nutrition Research, vol 53. Elsevier, pp 123-159

46. Warraky AE, Shayeb HAE, Sherif EM (2004) Pitting corrosion of copper in chloride solutions. AntiCorros Methods Mater 51(1):52-61

47. Wood JM, Wang HK (1983) Microbial resistance to heavy metals. Environ Sci Technol 17(12):582A$590 \mathrm{~A}$

\section{Tables}


Table: 1. Experimental strategy on a biocorrosion experiment in cooling water system

\section{S.no Systems Experimental plan}

1. control $400 \mathrm{~mL}$ in sterile cooling tower water containing $1 \%$ of nutrient broth (NB)

2. Systems $400 \mathrm{~mL}$ in sterile cooling tower water containing $1 \%$ of nutrient broth (NB) with $1 \mathrm{ml}$ of consortium (B. thuringiensis EN2, $T$. aidingensis EN3 and B. oleronius EN9)

3. Systems $400 \mathrm{~mL}$ in sterile cooling tower water containing $1 \%$ of nutrient broth (NB) with II $1 \mathrm{ml}$ of consortium and $50 \mathrm{ppm} \mathrm{AgNO}_{3}$

4. Systems $400 \mathrm{~mL}$ in sterile cooling tower water containing $1 \%$ of nutrient broth (NB) with III $\quad 1 \mathrm{ml}$ of consortium and $50 \mathrm{ppm}$ RYRE

5. Systems $400 \mathrm{~mL}$ in sterile cooling tower water containing $1 \%$ of nutrient broth (NB) with IV $1 \mathrm{ml}$ of consortium and 50ppm AgNPs.

Table: 2 Average weight loss and corrosion rate of Cu metal

\begin{tabular}{|lllll|}
\hline S.no & Sample & Average weight loss $(\mathrm{g})$ & Corrosion rate $(\mathrm{mm} /$ year) & Inhibition efficiency $(\%)$ \\
\hline 1 & Control & $0.0016 \pm 1$ & 0.017 & - \\
2 & System I & $0.0039 \pm 2$ & 0.043 & - \\
\hline 3 & System II & $0.0008 \pm 2$ & 0.009 & 47 \\
\hline 4. & System III & $0.00060 \pm 2$ & 0.006 & 61 \\
\hline 5. & System VI & $0.00027 \pm 2$ & 0.002 & 82 \\
\hline
\end{tabular}

Table: 3 Electrochemical data of various bio corrosion system of Cu metal in cooling tower system

\begin{tabular}{|llll|}
\hline S.No & Systems & \multicolumn{2}{l|}{ Polarization data } \\
\hline & & Ecorr $(\mathrm{mV})$ & Icorr $\left(\mathrm{A} / \mathrm{cm}^{2}\right)$ \\
\hline $\mathbf{1}$ & Control & -522 & $3.6 \times 10^{-6}$ \\
\hline $\mathbf{3}$ & System I & -499 & $4.7 \times 10^{-7}$ \\
\hline $\mathbf{4}$ & System II & -467 & $3.5 \times 10^{-7}$ \\
\hline $\mathbf{5}$ & System III & -462 & $3.3 \times 10^{-6}$ \\
\hline
\end{tabular}




\section{$\mathrm{E}_{\text {corr }}$ - Corrosion potential, $i_{\text {corr }}-$ corrosion current}

\section{Figures}
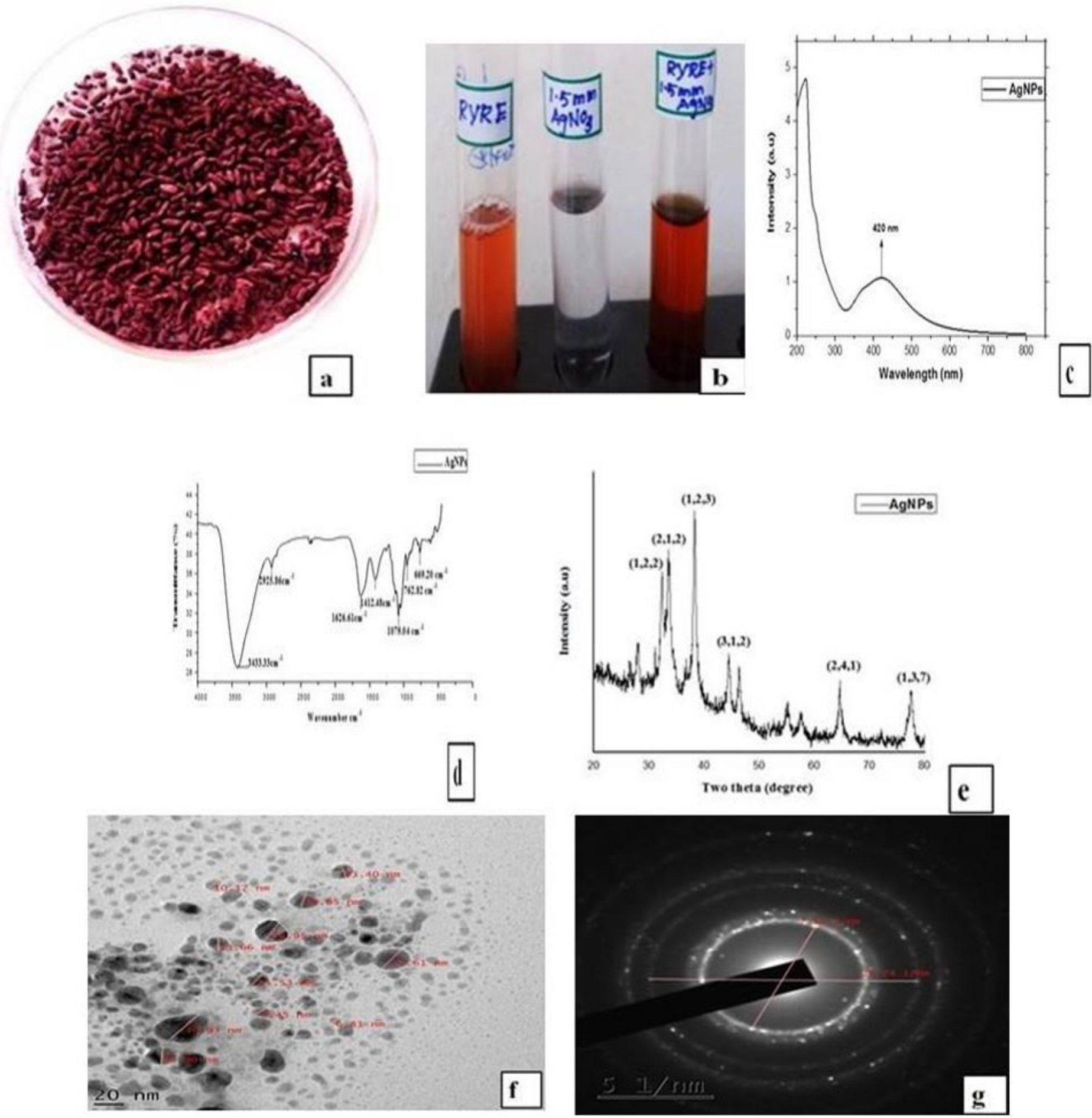

Figure 1 
Physical characterization of RYRE mediated AgNPs a) Red yeast rice. b) Visual observation of myco synthesized AgNPs. c) UV-Vis absorption spectrum of AgNPs with an intense peak at $420 \mathrm{~nm}$. d) Fourier Transform Infra-Red spectrum of AgNPs. e) X-ray diffraction of AgNPs. f) Transmission Electron Microscopic observation of AgNPs g) Selected Area Electron Diffraction (SAED) pattern taken from AgNPs.

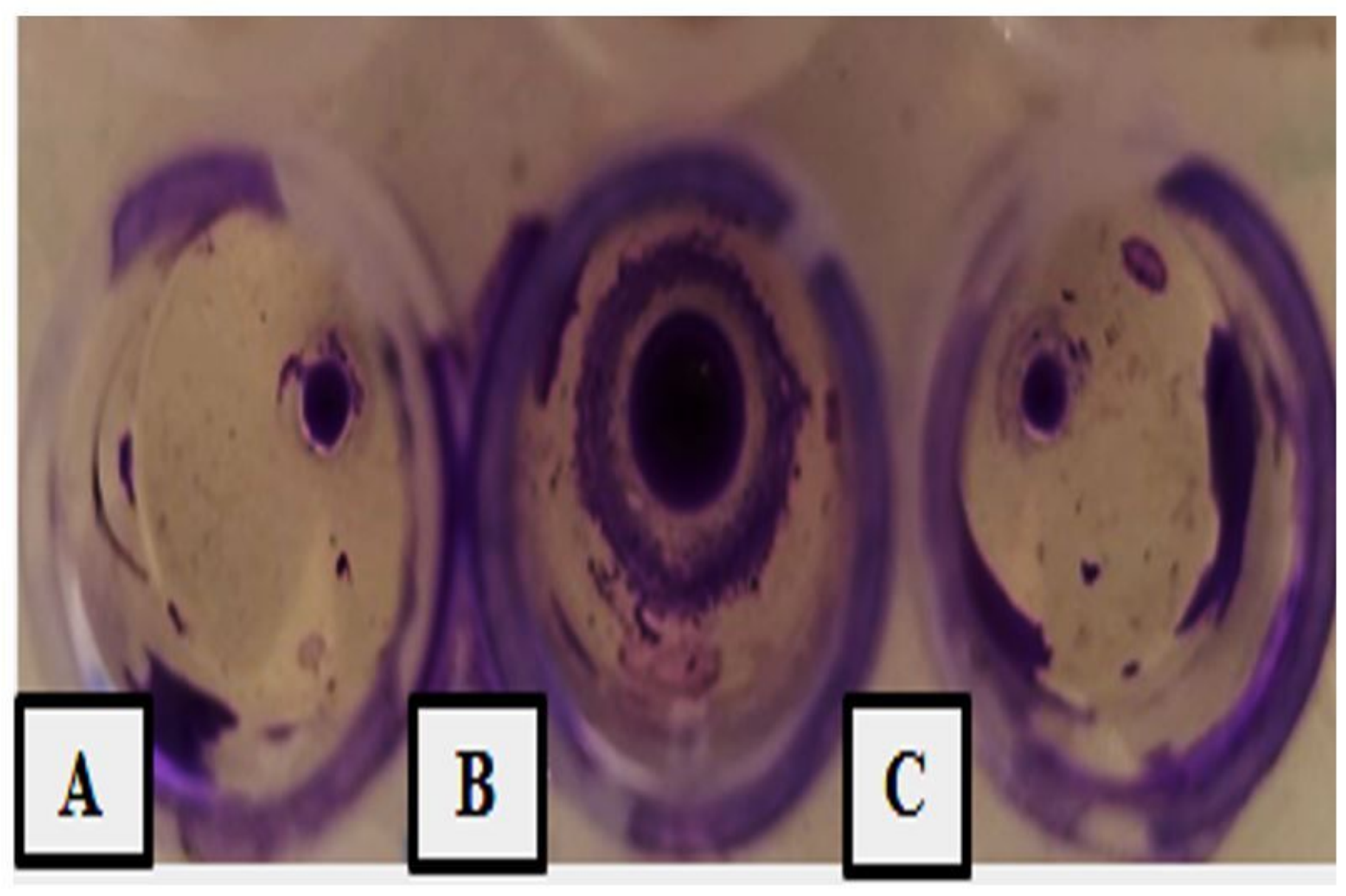

\section{Figure 2}

Biofilm formation in microtitre well plate (a) Nutrient broth (b) consortia (c) AgNP 


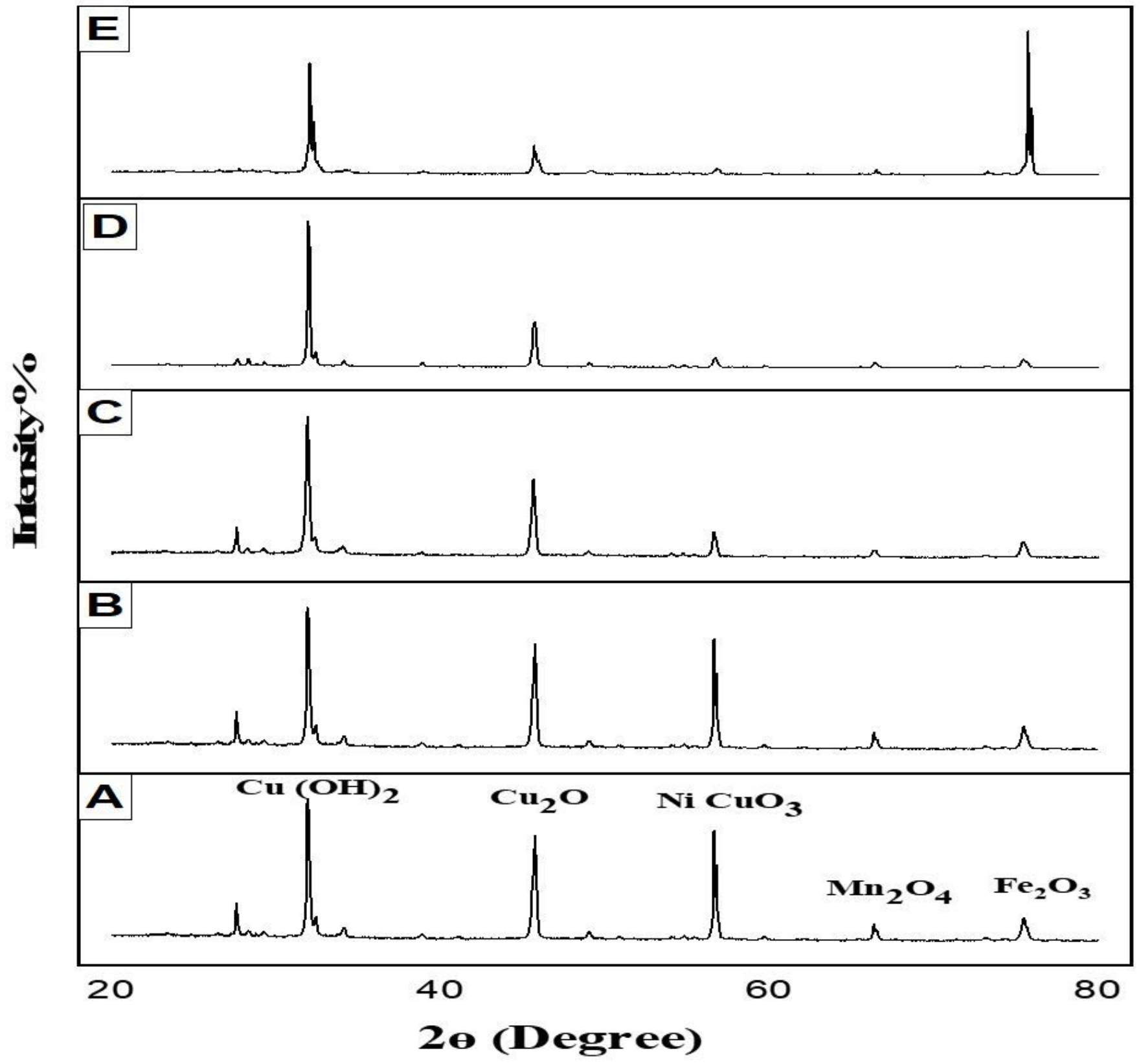

Figure 3

XRD pattern of corrosive Cu product (A) Control (B) Consortia (C) $\mathrm{AgNO}_{3}$ (D) RYRE (E) AgNPs 


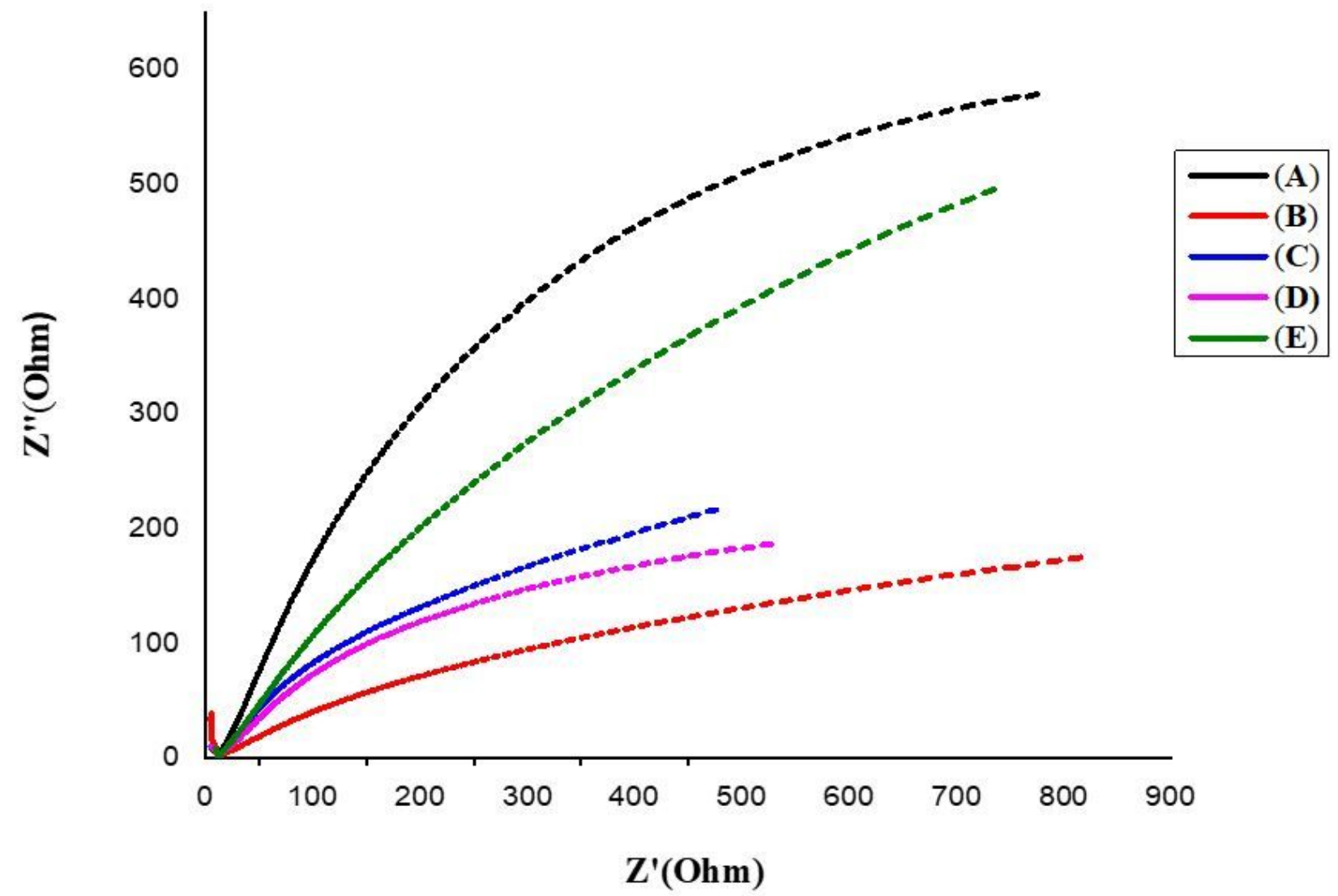

Figure 4

Nyquist plot/AC impedance spectra of Cu metal treated with various corrosion systems (A)Control (B) Consortia (C) $\mathrm{AgNO}_{3}$ (D) RYRE (E) AgNPs 


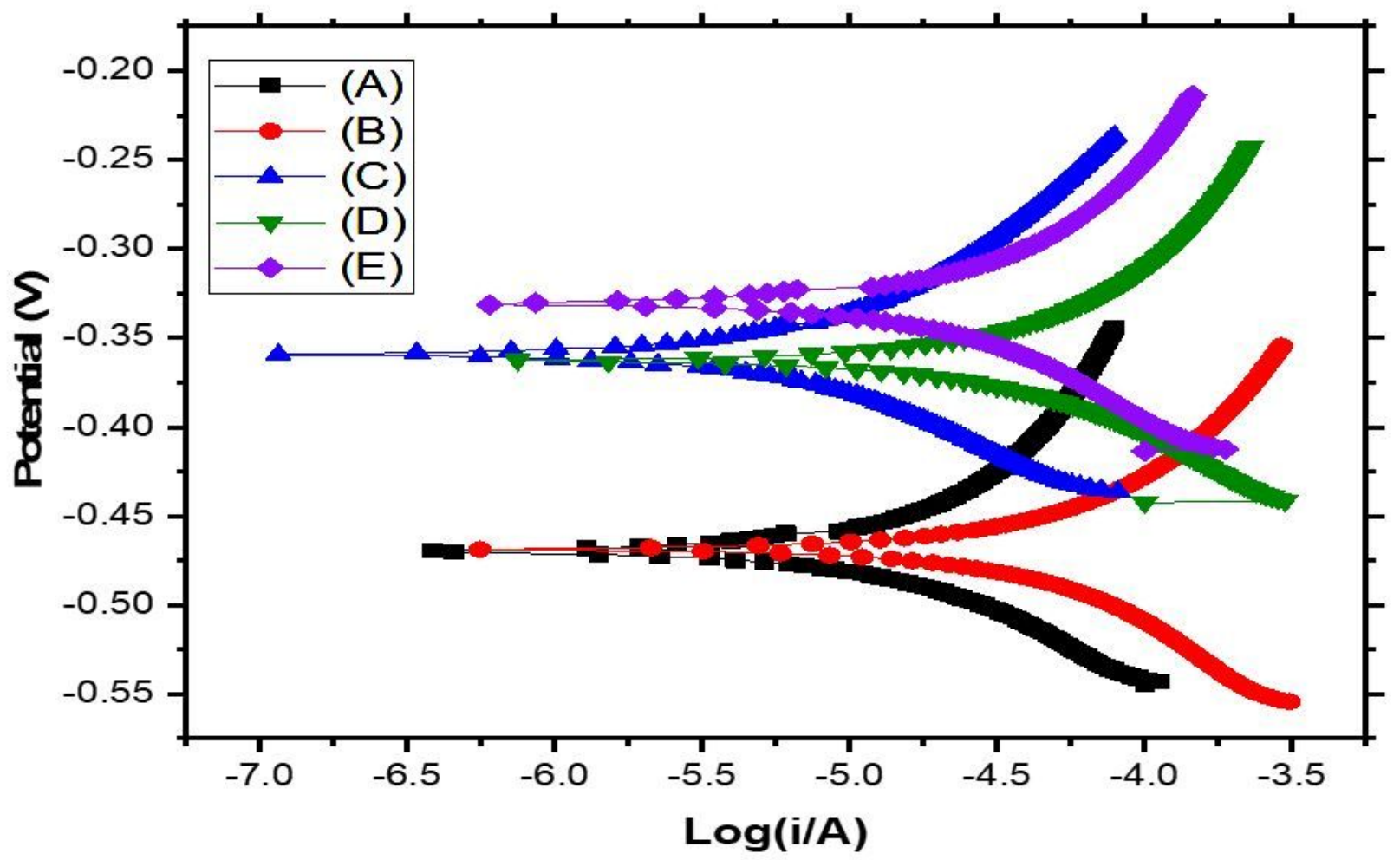

Figure 5

Polarization spectrum of various bio corrosion system (A) Control (B) Consortia (C) $\mathrm{AgNO}_{3}(\mathrm{D}) \mathrm{AgNPs}(\mathrm{E})$ RYRE 